\title{
English Connector as Binding Term for Conjunction and Relative Pronoun
}

\author{
Japen Sarage \\ University of Ahmad Dahlan, Yogyakarta, Indonesia
}

\begin{abstract}
As grammatical words, conjunction and relative pronoun play a similar role. They join clauses, phrases, and even words. The terms independent and dependent clauses have become popular for quite a long time. When the concept of clause and sentence meets at the presence of NP (Noun Phrase) and VP (Verb Phrase), there is a right to consider construction as an $\mathrm{S}$ or a sentence leaving the conjunction and relative pronoun as means of uniting device and leaving every NP-VP construction as equal units. By employing an embedding theory, we can see hidden parts of a sentence and their roles in other sentences. This article tries to see if it is still necessary to distinguish between dependent and independent clauses.

Keywords: connector, conjunction, relative pronoun
\end{abstract}

\section{Introduction}

Linguistic theory develops and its development yields linguistic groupings such as words, phrases, and clauses. A good example is the word class in English, which changes from time to time in accordance with its explanatory theory. To mention some language theories, which result in word class, Otto Jespersen (1933) classifies English words into eight classes, i.e., substantives, adjectives, verbs, pronouns, numerals, particles, provisional survey of inflection, and derivation of word classes (p. 38). The classification seems to root in the stem form of word.

In another fashion, Quirk (1985) classifies words into those of closed and open classes together with numerals and interjections as lesser classes (p. 67). The closed class includes those words of fixed forms, which receive neither inflectional nor derivational processes such as prepositions, pronouns, determiners, conjunctions, modal verbs, and primary verbs whereas the open class covers nouns, adjectives, full verbs, and adverbs. Similarly, DeCapua (2008) classifies words into a major class covering nouns, verbs, adjectives, and adverbs, and a minor class such as prepositions, pronouns, conjunctions, and qualifiers (p. 21).

In addition to the above mentioned word classes, Gelderen classifies English words into, lexical, grammatical, and hybrid words. The grammatical words include nouns, verbs, adjectives, adverbs, and prepositions while the grammatical words cover, coordinators, and complementizers. The hybrid class is pronoun, which resembles both grammatical as well as lexical words (Gelderen, 2010, p. 26).

Gelderen's proposal on coordinator and complementizer has inspired us to discuss their functions in a sentence. It is also important to agree on some grammatical terms in order to avoid confusion.

Japen Sarage, M.A., English Education, University of Ahmad Dahlan. 


\section{Coordinator or Connector}

The term coordinator or coordinating conjunction is used for the words capable of joining equal linguistic units ranging from word, phrase, and clause. The sameness of the linguistic is proved by their interchangeable position. Thus, it applies the rule $\mathrm{A}+\mathrm{B}=\mathrm{B}+\mathrm{A}$. The following sentence is a good example of coordinator at clause level.

(1) John left and Jane arrived.

(2) Jane arrived and John left.

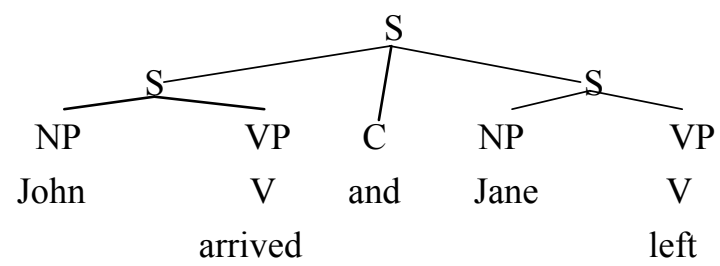

In the traditional view the two clauses, which, to Gelderen, are sentences Ss, are reversible so that they are called independent clauses. Though there is only a slight difference between the first and the reversed sentence, the following diagram shows that the sentence is additional to the first.

(3)

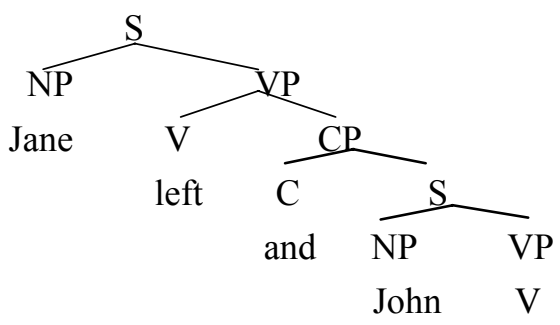

arrived

The above diagram shows that the sentence consists of two sentences, which are not exactly the same level. The second is additional to the first.

In the following sentence (4), the same conjunction and joins two NPs according to some grammarians, while other grammarians consider it as joining two sentences. By using the principle of embedding, the sentence can be best described in the following tree diagram (4).

(4) John and Jane work.

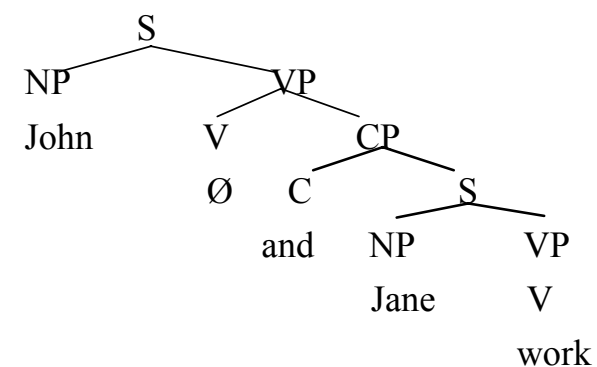

The above diagram shows that the NPs John and Jane share the same verb, which is expressed in the null verb. In other words, the connector does not join two NPs but two sentences. The above case does not apply to the word but because this word does not only fall into one word class. It falls into a conjunction as well as a preposition. The following diagrams prove the word class of the word but. 
(5) All students but Jane work.

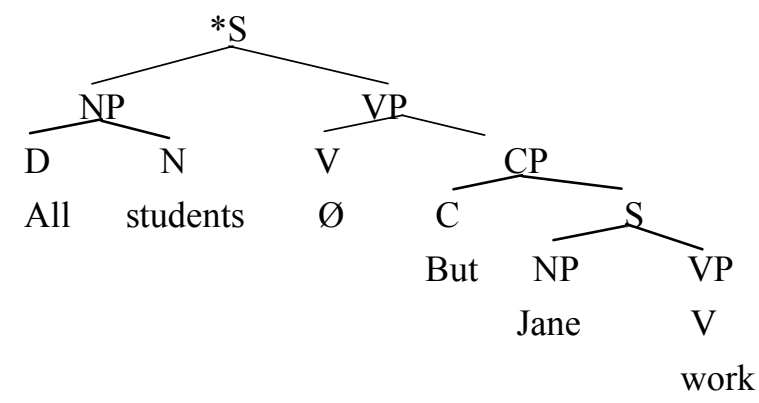

(6)

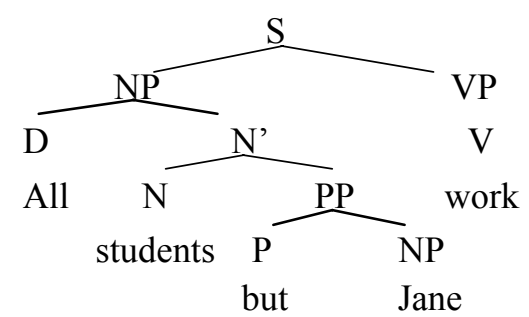

In (5) the diagram shows two verb slots one with a null the other with the verb work. This is not true because the two NPs all students and Jane do not share the same verb. In (6) on the other hand, the connector but joins the NP Jane to the NP all students. This proves that but is not a connector. It is a preposition together with the NP Jane functioning as a post-modifier to the head word students. Another proof, which shows but as a preposition is that all students and Jane are not reversible. Consider the following.

(7) *Jane but all students work.

The above sentence is not acceptable. Besides but functions as a preposition, it can also function as a connector. The following sentence exhibits but, which connects two sentences.

(8) Jane is talkative but John is calm.

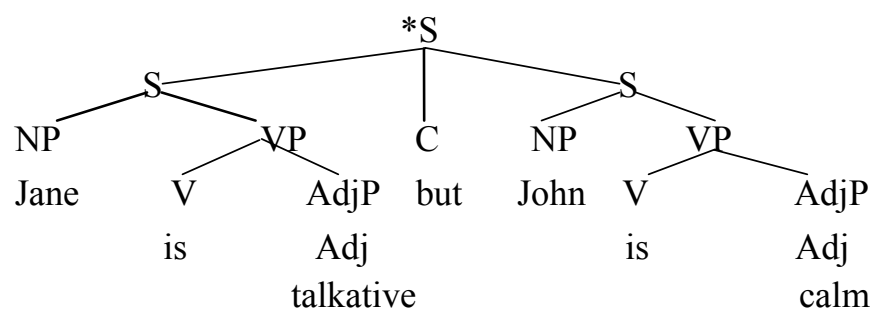

The above diagram is the traditional way of showing the same degree of clauses, i.e., independent clauses. As stated in the discussion above, these sentences are reversible but the order still plays a slight different role. The second adds the first. Thus, the following diagram might suit to the sentence.

(9)

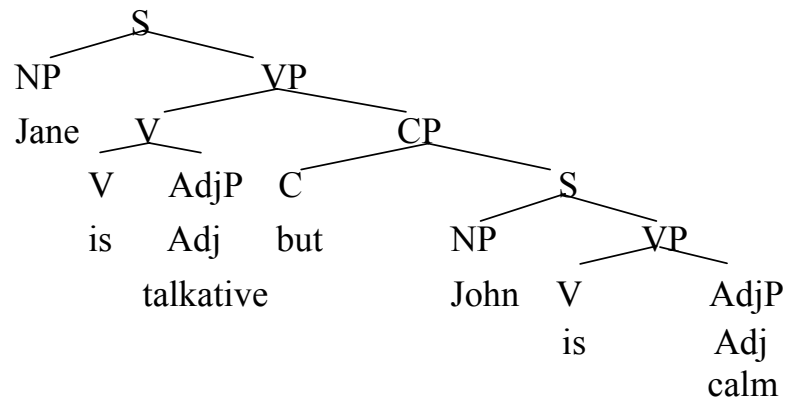


Though peripheral, the clause John is calm adds the first information. When it is reserved, it becomes the first information and the first becomes the second.

A conjunction may consist of more than one word comprising a function. The words as well as are labeled under one category - a conjunction or a connector. Thus, these words are not broken down into smaller units. (10) Jane cooks rice as well as vegetables.

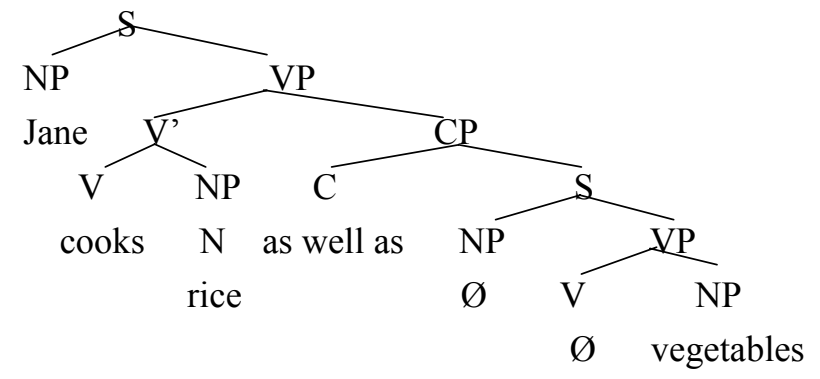

Besides a conjunction in the form of one and more than one words, there are conjunctions with more than one word, which are separated by other word or words. Traditionally, they are called correlative conjunctions. This fact presents a special technical problem in tree diagram. The use of node to represent emanation of the branches is introduced in generative grammar. The node is mainly used to generate branches of NP, VP, AdjP (Adjective Phrase), and AdvP (Adverb Phrase). Connectors rarely produce node but for the sake of describing a correlative conjunction, which can be called separate connector, the use of node is employed to show the parts of separate connectors. In the following diagram, the writer introduces the use of node for connector phrase (CP). The node generates another $\mathrm{CP}$ branch in the other side.

(11) He either likes oranges or mangoes.

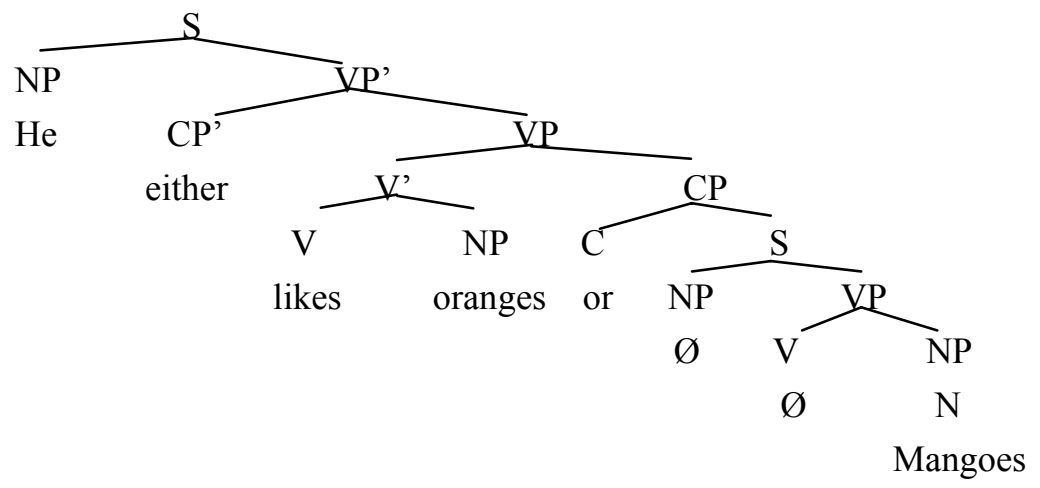

The use of node for $\mathrm{CP}$ is introduced here to relate parts of correlative conjunction.

\section{Zero Connector}

A connector, which is traditionally called relative pronoun, can present a question whether it merely functions as a pronoun, connector, or both. In the following sentence, the words the letter functioning as a complement to the verb received and the verb group had sent are embedded so that the latter is represented by null Ø (for an embedding process see Crystal, 2008, p.167). 
(12) She received the letter, which I had sent.

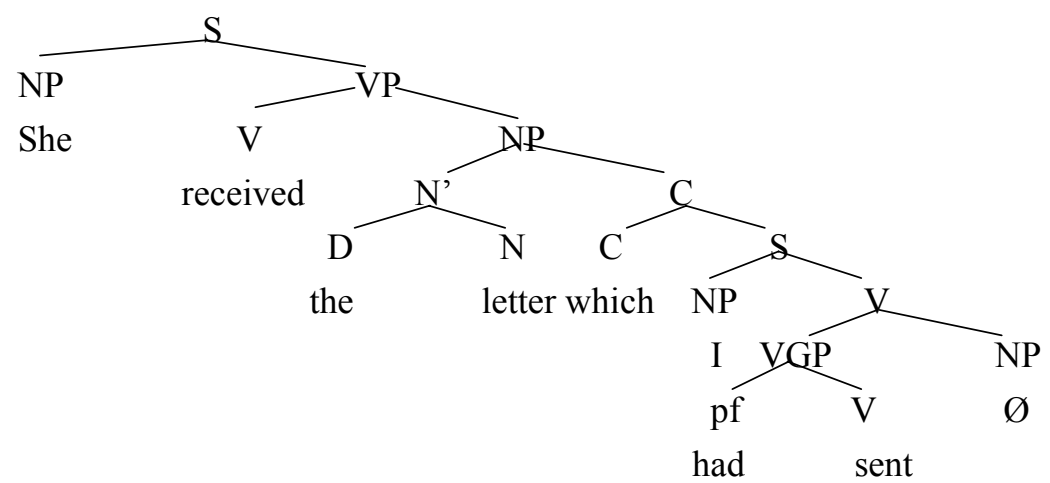

From the above diagram, it is clear that the function of connector is separate from the function of pronoun. The connector which in the above sentence can be omitted due to the function of the words the letter in the clause. Thus, the sentence can be diagrammed as the following.

(13) She received the letter I had sent.

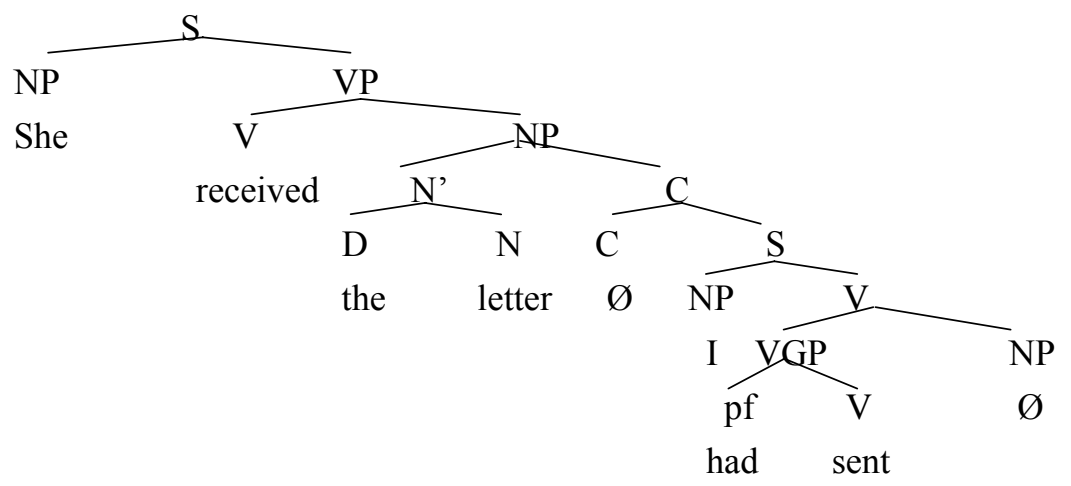

Although there is a relationship between the connector and the embedded words, i.e., which for a thing and whom or who for a person, we can call it as a predicting connector. The different roles between a pronoun and a connector can be best described in the following sentence.

(14) The letter, which was sent, has been received.

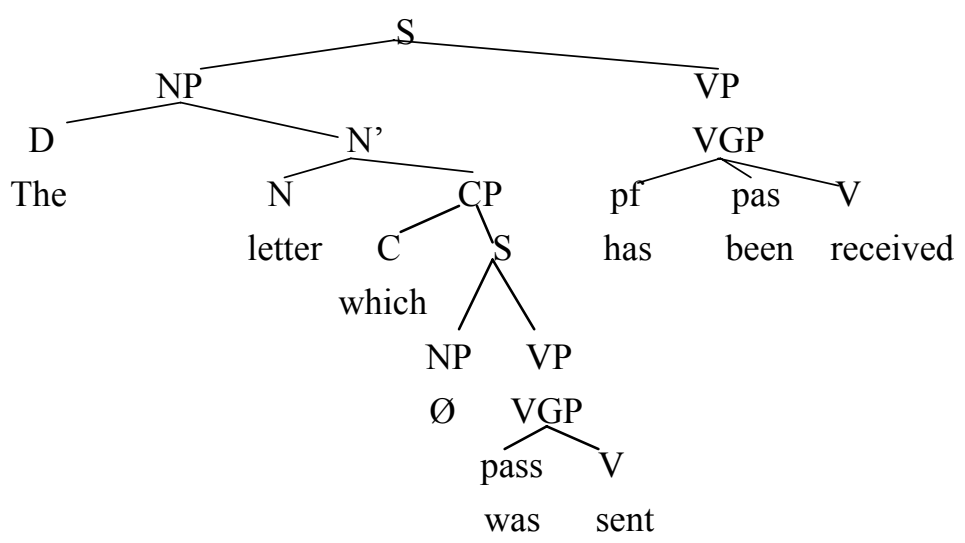

The embedded part in the above sentence is the NP so that the NP in the second clause is omitted and represented by null $\varnothing$. From the above description it is clear that the connective function is different from the 
pronominal function. Fountaine (2013) considers which as having a double duty (p. 29).

(15) When she was walking along the street, she picked up flowers.

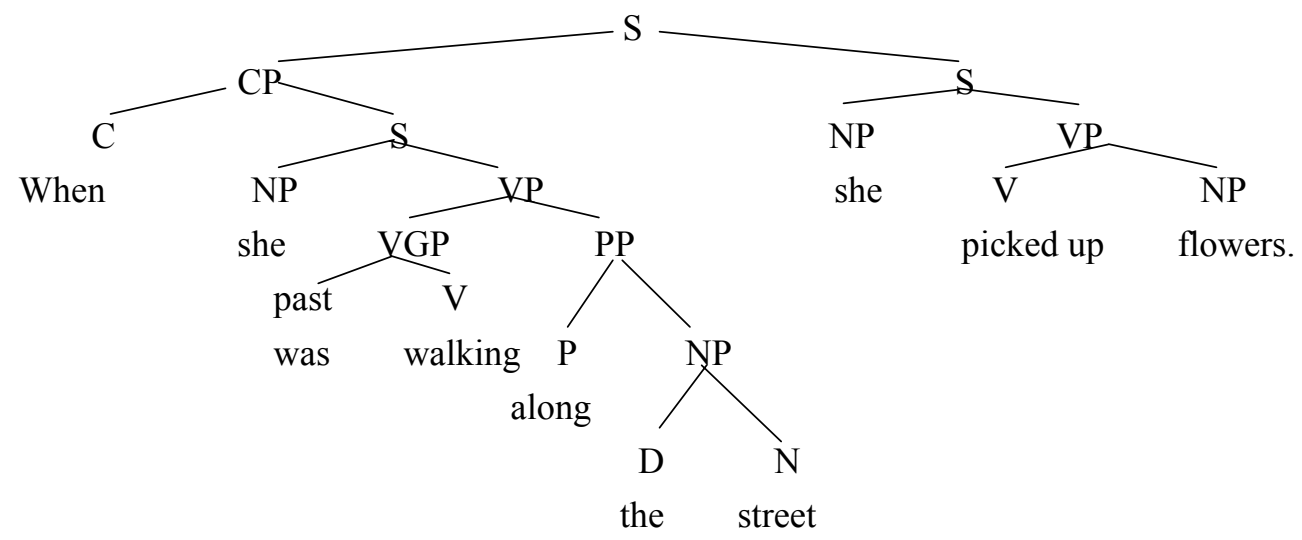

(16) Walking along the street, she picked up flowers.

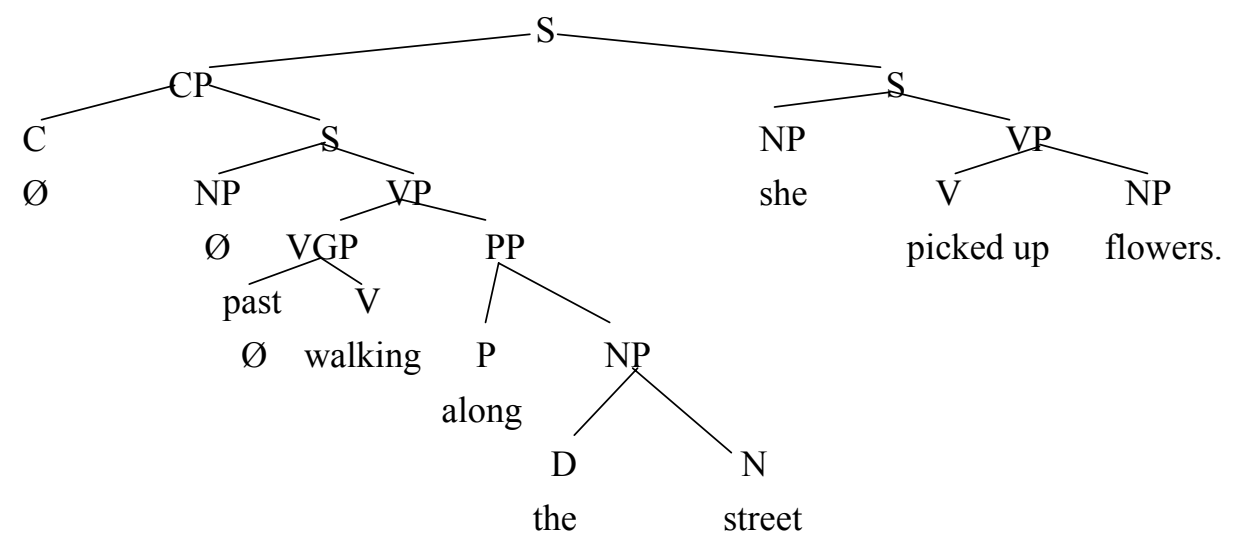

By comparing (15) and (16) we can see the embedded parts and the zero elements. Since the connector is only one (15), when it is not present as in (16) we can call it a zero connector. The same case happens to the member of the verb group past (VGP). This is not a part of embedded element but a zero element. On the other hand, the NP in (16) is an embedded part of another S, so it is null Ø.

\section{Conclusion}

From the brief discussion, we can conclude that the judgment for word class develops. Conjunctions and relative pronouns have the same function. The notion of clause and sentence is almost the same so that the term sentence is preferred to show the main principal of a sentence. An embedding process is suitable the description of a sentence in two-branch tree diagram principle. Embedded parts are represented by null, which is the same with the symbol of zero parts. Linguistic units containing NV + VP can be joined with similar construction by using a connector, which can be either present or absent.

\section{References}

Crystal, D. (2008). A dictionary of linguistics and phonetics. Malden, USA: Backwell Publishing.

DeCapua, A. (2008). Grammar for teachers. New York: Springer.

Fountaine, L. (2013). Analysing English grammar. Cambridge, Cambridge University Press.

Gelderen, E. van. (2010). An introduction to English grammar. Amsterdam: John Benjamin Publication. 
Jespersen, O. (1933). Essentials of English grammar. London: Routledge.

Quirk, R., Greenbaum, S., Leech, G., \& Svartvik, J. (1985). A comprehensive grammar of the English language. London: Longman.

Wekker, H. (1985). A modern course of English syntax. London: Routledge.

\section{Appendix: About the Author (Japen Sarage, M.A.)}

He was born in 1959. After finishing his teachers' training for elementary school (high school level) in 1979, he continued his study at English Education Department and finished it in 1986. Then he served as a lecturer in English Department of Academy of Foreign Languages. After finishing his master degree in linguistics, he works as a lecturer at University of Ahmad Dahlan, Yogyakarta, Indonesia.

His major interests are English, Arabic, Russian, and Spanish languages besides his mother tongue Javanese and his second language Indonesian. 